Arqueología y Sociedad,

№ 20, 2009

\title{
OBSERVACIONES DE REgULARIDADES EN LAS TIRAS DE TOKAPUS DE ALGUNOS QUEROS DE LA ÉPOCA COLONIAL
}

Katalin Nagy*

\section{Resumen}

El presente artículo hace un estudio de los tokapus a partir de la descripción de temas y colores en alfombras, tapices, cerámica, queros, etc., y además intenta descifrar el contenido informativo con el fin de comprender el entorno cultural y las relaciones que implica el manejo de esta información.

\section{Palabras clave}

Tokapus, motivos, queros, estilos, escenas.

\begin{abstract}
The present article does a study of the tokapus from the description of topics and colors in carpets, carpets, ceramics, queros, etc., and also it tries to describe the informative content in order to understand the cultural environment and the relations that the handling of this information implies.
\end{abstract}

\section{Keywords}

Tokapus, motives, queros, styles, scenes.

\footnotetext{
* Freie Universität Berlin
} 


\section{INTRODUCCIÓN AL ESTUDIO DE LAS TIRAS DE TOKAPUS}

\section{I.1. La investigación de los tokapus y sus limitaciones}

Los tokapus son signos geométricos y abstractos separados unos de otros por un marco rectangular. En algunos casos estos signos pueden mostrar un motivo reconocible, aunque el significado original permanece en la mayoría de ellos oculto y se les intenta buscar una interpretación simbólica. Los tokapus son decoraciones típicas del tiempo de los inkas. Previamente ya los encontramos en las culturas de Huari y Tiahuanaco y posteriormente se han conservado durante la época colonial. En las superficies decoradas los tokapus aparecen en grupos secuenciales, a menudo en líneas.

Los tokapus se presentan en objetos diferentes, por ejemplo, en prendas de vestir de las elites incaicas y coloniales, también decoran alfombras y tapices. Igualmente se pintaron en objetos de cerámica, como los aríbalos y platitos de ofrenda. A ellos deben sumarse las pacchas, objetos especiales para las libaciones, y los vasos para beber, que se fabricaban de metal o madera. Los últimos se denominaron en quechua por su material queros. En los tejidos y en los vasos libatorios los tokapus forman una sola cenefa o varias paralelas. En este artículo quisiera dedicarme concretamente a las cenefas de un grupo escogido de queros.

El estudio de los tokapus se basa en la descripción de la variación de temas y colores, y además en descifrar el contenido informativo para la cultura y comprender las relaciones entre ellos. Debido al gran número y la variación de tokapus, su catalogación e interpretación permanecen sin resolver. La interpretación resulta más difícil cuanto más completa se intenta hacerla, tal como lo intentaron los investiga- dores V. de la Jara y T. Barthel. No obtuvieron resultados satisfactorios.

Es prácticamente imposible comprender los tokapus si queremos hacerlo todo en sólo un paso. Pero en cambio sí parece posible tratar de explicar su significado dentro de un contexto más reducido. Por ejemplo, los cambios culturales ocurridos en la época colonial llevaron a un cambio en la decoración de los queros ${ }^{1}$. Los queros de la época incaica y preinca se decoraban también con figuras geométricas, sin embargo, éstas eran mucho más sencillas. Su superficie, en lugar de pintarla, se rellenaba con finas líneas paralelas incisas. Los tokapus en los queros aparecieron más tarde y con ellos cambió toda la imagen de la superficie ${ }^{2}$. Es de suponer que antes de que aparecieran las versiones en color de los queros, estas decoraciones se realizaban en los tejidos. Los tokapus textiles son más complejos y diferenciados, lo cual dificulta mucho más su catalogación.

\section{2. Presentación de mi método e intención}

Propongo que, antes de llevar a cabo una completa investigación de los tokapus, nos ocupemos solamente de los que aparecen en los queros. El objetivo sería atribuir a cada símbolo un sentido o interpretación e incluso una relación justificada con el tokapu colindante. Sin embargo, debido a los escasos resultados sobre las informaciones contenidas en los tokapus, hasta ahora no es posible establecer un sistema completo de contenidos y relaciones entre las diferentes unidades gráficas. Por eso me parece razonable empezar un intento de investigación sobre algunos tokapus y de las relaciones entre ellos.

Esta idea no es nueva. Los trabajos de Cummins $^{3}$ y Silverman ${ }^{4}$ son ejemplos de este tipo de aproximación. Mientras Cummins trata la apari-

1 Me refiero a los cambios por ejemplo en la producción de los uncus, que antes estaba organizada centralmente.

2 Cronología (Rowe, 1961 y Liebscher, 1986).

1988, La historia del motivo «Inka-key».

1994, Interpretación del motivo «el rombo cuatripartito» o «el diamante cuatripartito». 
ción y el uso de un tema desde un punto de vista histórico, Silverman lo hace desde una perspectiva etnológica. En este trabajo, intento utilizar un método centrado en el aspecto gráfico y no en el del contenido. Quisiera mostrar que los tokapus de un tipo concreto de quero, presentan un número limitado de temas y sus variaciones parecen respetar una cierta regularidad en sus posiciones en una secuencia. Aunque en este artículo no quisiera tratar el contenido de los tokapus, al final voy a hablar de algunas suposiciones sobre cinco temas de ellos.

\section{LA INVESTIGACIÓN}

\section{II.1. La delimitación del grupo de queros investigados}

Cuando se trata de hacer investigaciones iconográficas, es importante mantener el objeto de estudio bien delimitado y en su contexto. Por esta razón he escogido para mi análisis un tipo de quero que mantiene una uniformidad en la forma y en la disposición de la decoración. Para ello se escogió secuencias de tokapu combinadas con escenas complejas 5 .

\section{II.2. Distribución de la superficie y tipos de decoración}

La primera subdivisión de las escenas representadas la definió J.H. Rowe en el año 1961, diferenciando entre free style y formal style $e^{6}$, su intención era establecer una cronología. Liebscher clasificó los queros de un modo más diferenciado según su forma y decoración. La clasificación más reciente y diferenciada se está llevando a cabo en la colección de queros del Museo de América de Madrid? . Debido a que estas clasificaciones no aportan a mi trabajo ningún dato nuevo esencial, he decidido tomar la de Liebscher.

Para mi investigación he tenido 28 ejemplares a mi disposición, todos extraídos de textos publicados. Las decoraciones de diecinueve de ellos han sido desarrolladas por completo, en tres se han dibujado solamente las escenas y se han fotografiado los queros enteros. De los seis restantes sólo existen fotos: dos con la imagen completa del quero (estos los he podido dibujar) y cuatro en los que sólo se puede apreciar la mitad del recipiente ${ }^{8}$. Mis afirmaciones las he hecho en base a la observación de estos 28 ejemplares. Valdría la pena ampliar la muestra para verificar los resultados. Los queros que he escogido pertenecen, según la clasificación de Liebscher, a los grupos B y $\mathrm{C}^{9}$. Los grupos $\mathrm{B}$ y $\mathrm{C}$ los denomino, en relación a la longitud y complejidad de las escenas, «largas» (grupo B) y «cortas» (grupo C), respectivamente.

La superficie de los queros del grupo B se divide en tres zonas horizontales. En la parte de arriba hay una escena, en la mitad hay una tirada continua de tokapus y en la parte de abajo se hallan representados motivos florales. En el grupo C la decoración esta repartida en dos o tres tiras horizontales y la parte de arriba está separada en dos mitades. Una de ellas está además subrayada al borde por una línea vertical. Mientras que una mitad está rellena con una escena «corta», la otra muestra tres figuras bien delimitadas: dos motivos de tokapus combinados con un motivo floral.

De los 162 ejemplares investigados, 26 (16\%) los clasificó Liebscher en el grupo B. Si les sumamos el número de los queros del grupo C (58) el resultado es de 84 queros con líneas de

5 Según el estimado de de la Jara, sólo el 10 al 15 \% de los queros mostrarían tokapus (de la Jara, 1972: 35).

6 Rowe 1961: 336.

7 Ramos et al. 1998: 113ss.

8 Verena Liebscher ha catalogado 396 queros en 16 museos y colecciones, de éstos 337 mostraban pintura policroma. En su trabajo investiga 162 piezas en cuanto a sus «escenas largas», estos datos permiten hacer un estimado de la cantidad de queros con «escenas largas».

9 Liebscher 1986: 23, lám. III. 


\section{ESCENAS CORTAS}

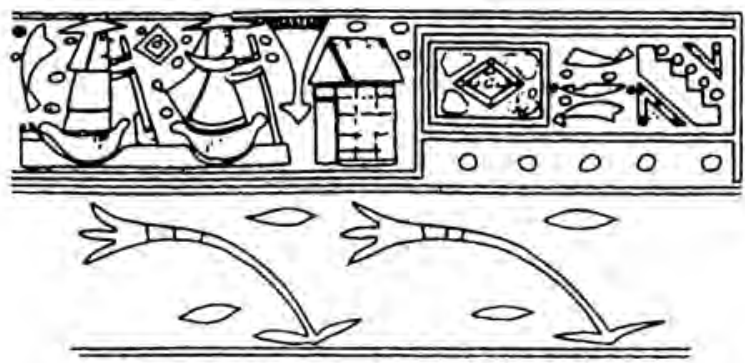

Fig. K1

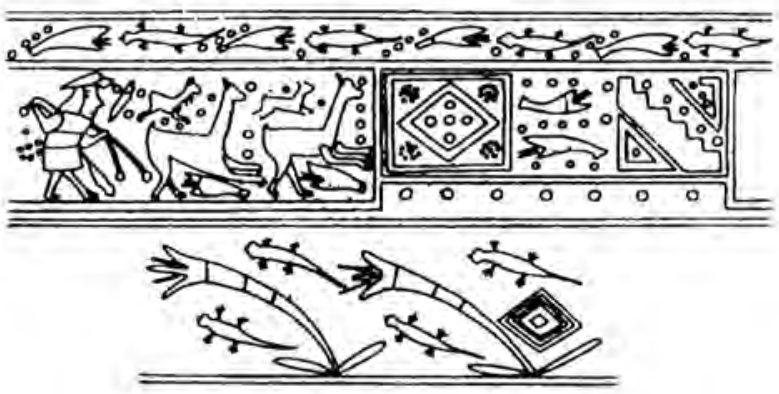

Fig. K2
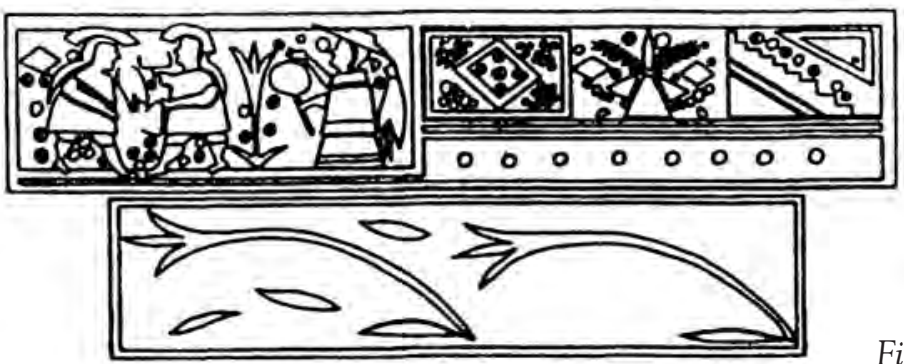

Fig. K3

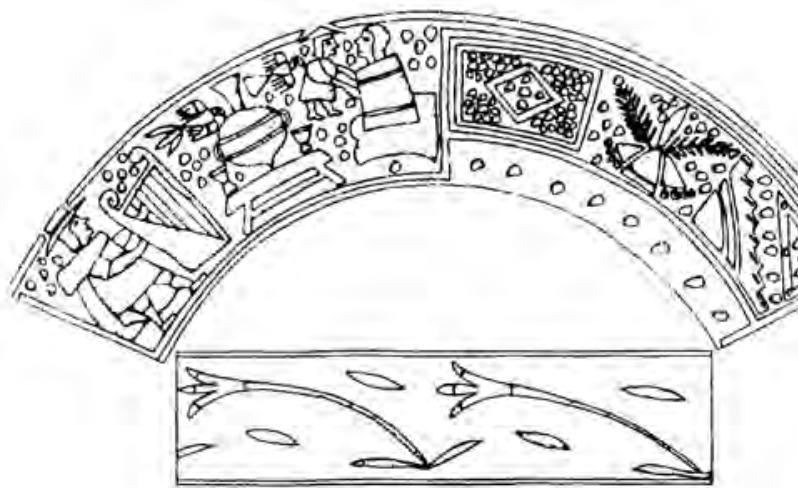

Fig. K4 


\section{ESCENAS CORTAS}

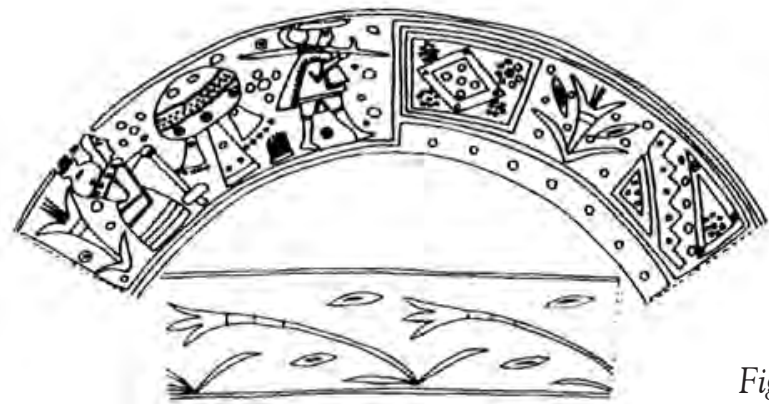

Fig. K5

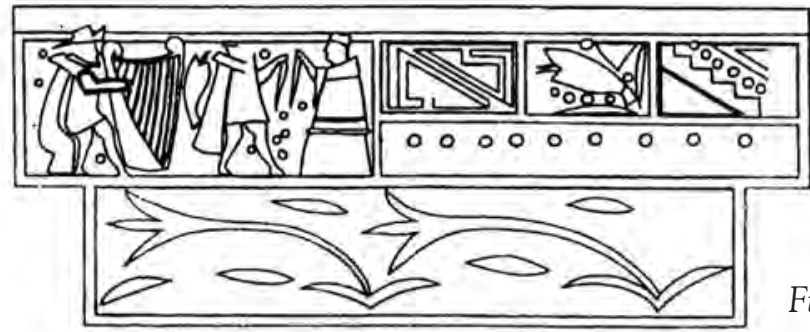

Fig. K6
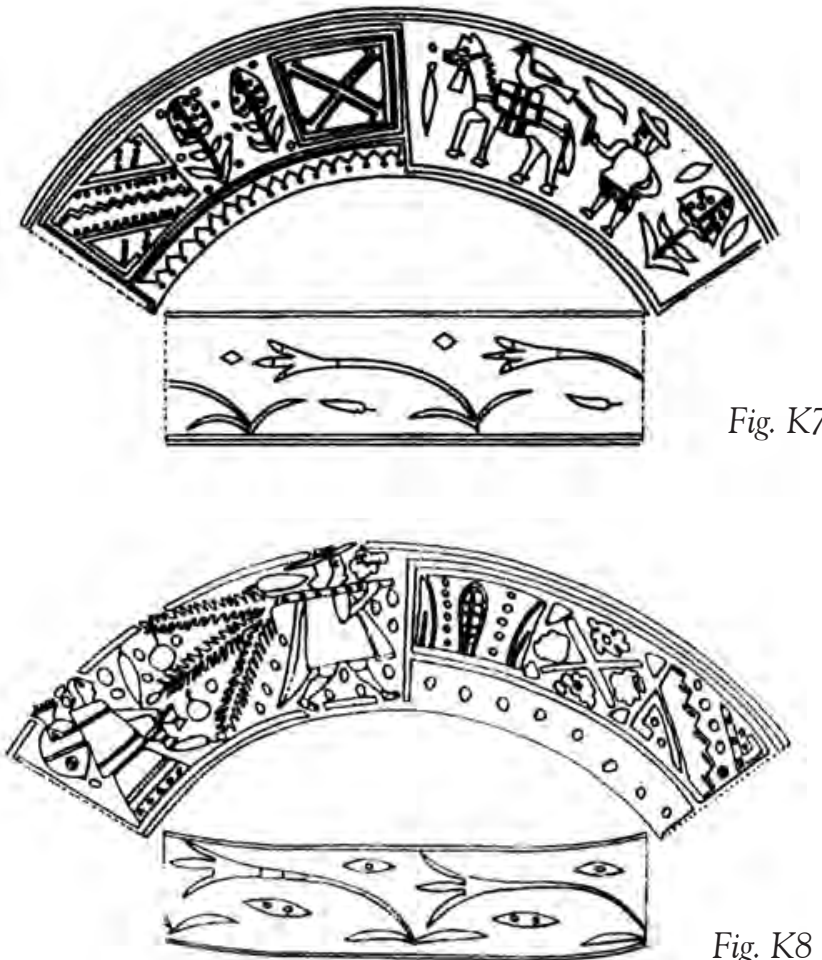

Fig. K8 
LÁMINA I. TIRAS DE TOCAPUS EN LAS “ESCENAS CORTAS”

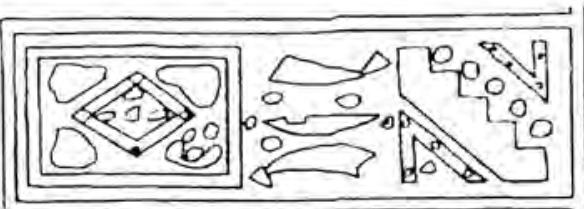

Fig. K1

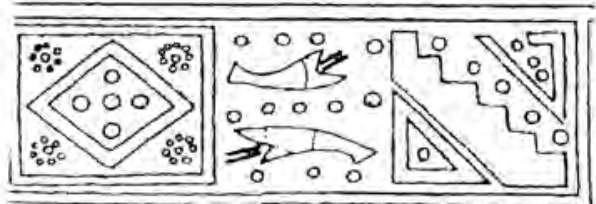

Fig. K2

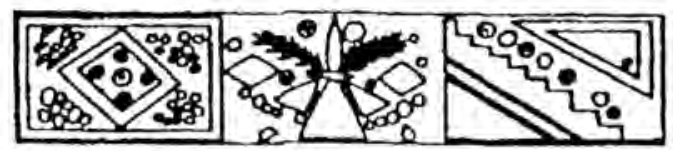

Fig. K3

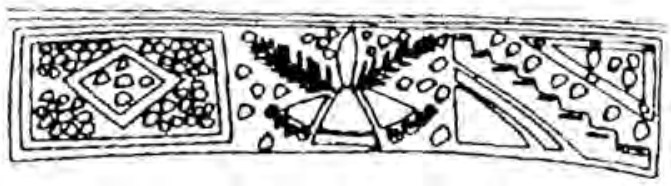

Fig. K4

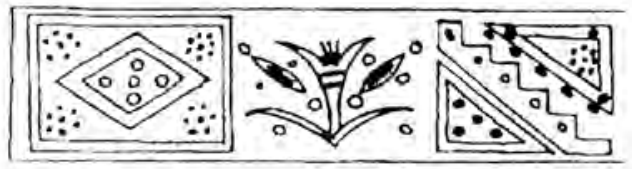

Fig. K5

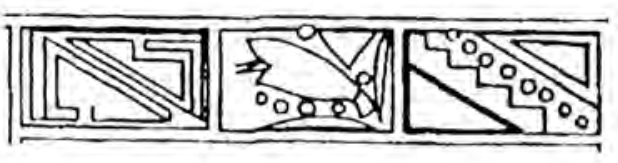

Fig. K6
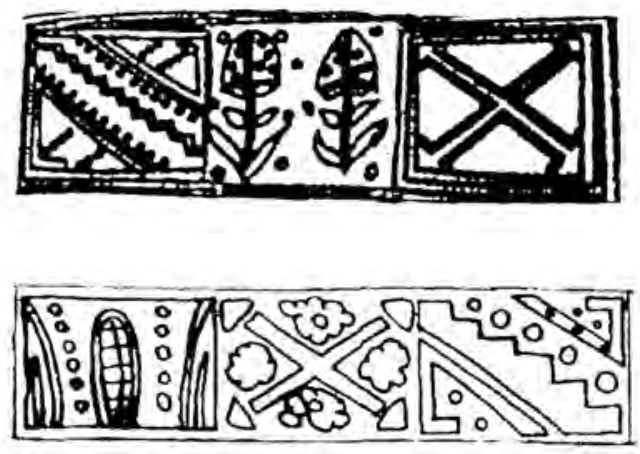

Fig. K8 
tokapus «largas» o «cortas». Los dos grupos juntos nos dan la mitad de los queros investigados por Liebscher. Llama la atención la cantidad relativa, 58 ejemplares con «escenas cortas» de un total de 162 queros. Representan casi el 36\% de los queros investigados por Liebscher y el $70 \%$ de los queros decorados con tiras de tokapus.

El contenido de las «escenas cortas» se reduce a pocos temas como la agricultura, el transporte con llamas o mulas, escenas con casas y lucha entre dos figuras. Las «escenas cortas» no representan nunca la gran fiesta de la cosecha, ni motivos con el «arco iris». A menudo muestran motivos de música y baile, pero nunca del baile de los Chunchos ${ }^{10}$. Estas escenas se encuentran en una parte del quero. En la otra encontramos los dos tokapus acompañantes, separados o, según como se mire, unidos por una flor.

\section{II.3. Delimitación de los motivos}

Antes de entrar a la diferenciación de los motivos, hay que hacer hincapié del hecho que la reducción a dibujos en blanco y negro de tokapus hace perder la información contenida en los originales en color. La técnica de producción específica de los motivos empieza con el tallado en madera de las líneas básicas que marcan la estructura de los motivos. La mayoría de las veces la reproducción muestra estas líneas. Pero la coloración constaba de dos pasos: primero se rellenaban las líneas grabadas con una pasta de color y después se repartía con un pincel el resto de los colores por la superficie ${ }^{11}$. Las superficies de colores se podían adornar después con líneas finas y puntos. Esta complejidad no se puede conseguir con las reproducciones lineares. Pero ellos sí aportan los elementos básicos y esenciales para mi investigación.

\section{II.3. A: «Escenas cortas»}

Ocho piezas ejemplo de las «escenas cortas» recolectadas aparecen en las figuras K1 - K8. Las unidades que acompañan a las «escenas cortas» y que constan de tres motivos, son llamativamente parecidas: cada una tiene dos tokapus en ambos lados y un motivo floral en el centro. Este motivo floral del medio varía de un caso a otro y está representado por todas las clases de flores conocidas $^{12}$ que aparecen en la parte baja de los queros con «escenas largas», excepto la flor redonda llamada chimpu-chimpu13. La última, sin embargo no es motivo de tokapu, ya que no se encuentra enmarcada en el rectángulo típico de éstos.

En los ocho ejemplares, los dos motivos de los lados son ampliamente parecidos, lo cual me lleva a suponer que se trata en realidad del mismo motivo, por lo cual éstos deben considerarse variaciones de un mismo motivo base. Este parecido se muestra en las figuras $\mathrm{K} 1$ - K8. En los ocho ejemplos se puede apreciar en una posición lateral una escalera que une la esquina izquierda de arriba con la de abajo a la derecha.

La otra posición lateral aparece ocupada preferentemente por un tokapu con rombo. En tres casos aparecen también otros motivos. A partir de estos cinco motivos distintos voy a diferenciar entre cinco grupos, compuestos por variantes de un motivo base.

Mi suposición principal es que los dos tokapus laterales están estrechamente relacionados, por lo que respecta a la forma, con dos motivos base o ideas ${ }^{14}$. Con ello quiero decir al mismo tiempo que posiblemente no exista ningún motivo base de los tokapu, sino una idea base.

En los tokapus se trata de un motivo abstracto. Una superficie delimitada por un rectán-

10 Liebscher 1986: 24, Tablas.

11 Kaplan et al. 1999.

12 Compárese Liebscher 1986 y Flores Ochoa 1998.

13 Chimpu-chimpu (Fuchsia boliviana).

14 Estas ideas apoyarían interpretaciones de Cummins, que habla sobre el cambio muy rápido de las formas de representación en el paso de la época inca a la colonial. 


\section{ESCENAS LARGAS}
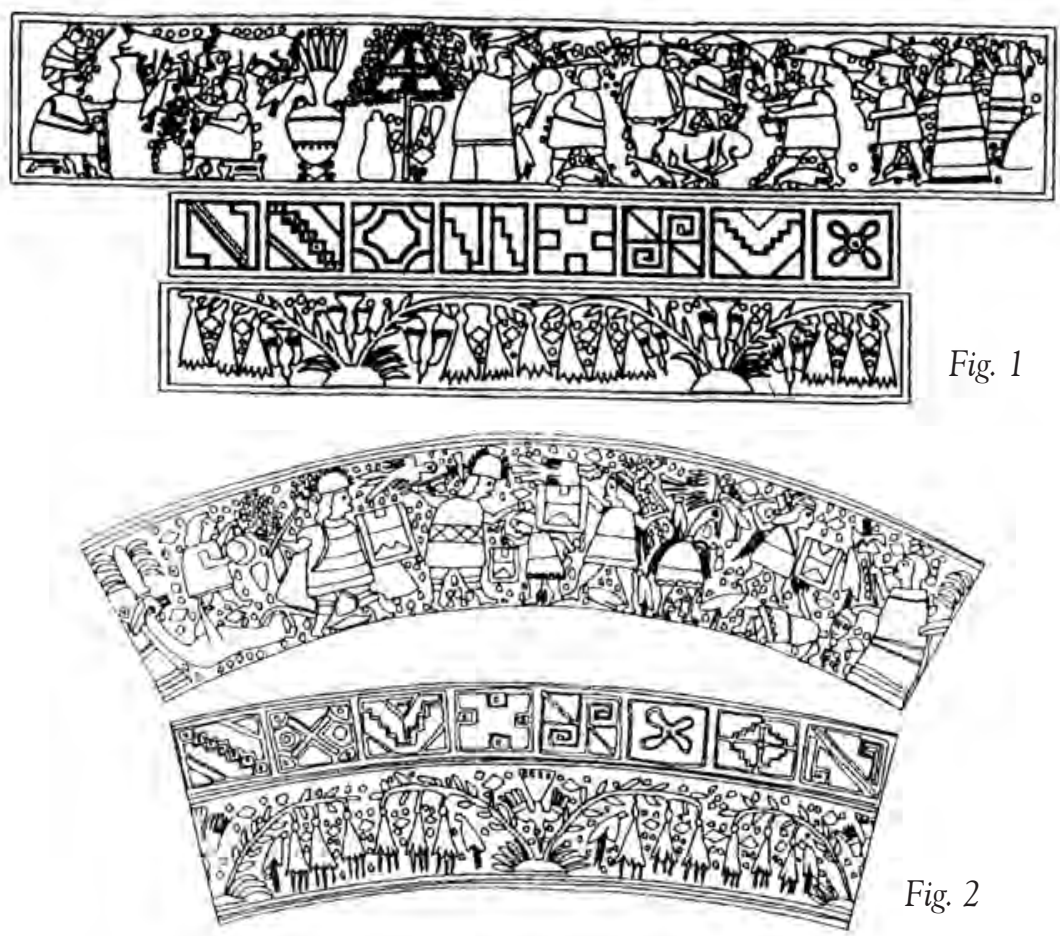

Fig. 2
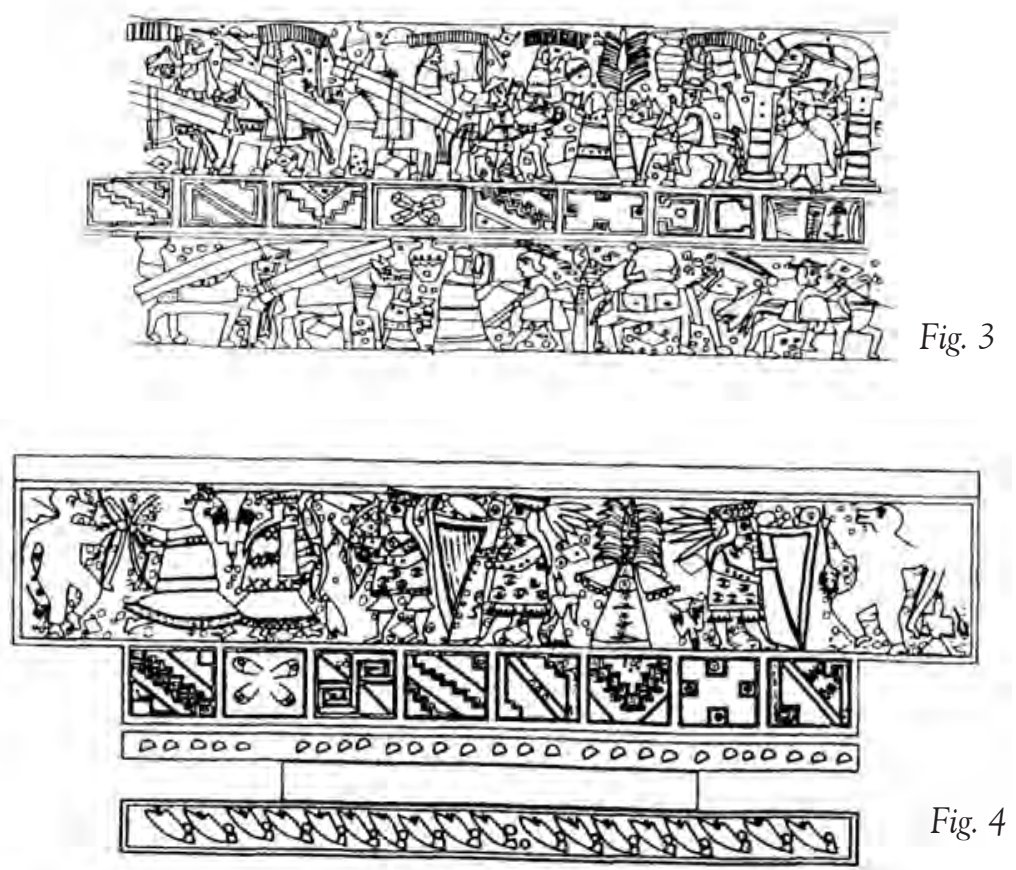


\section{ESCENAS LARGAS}
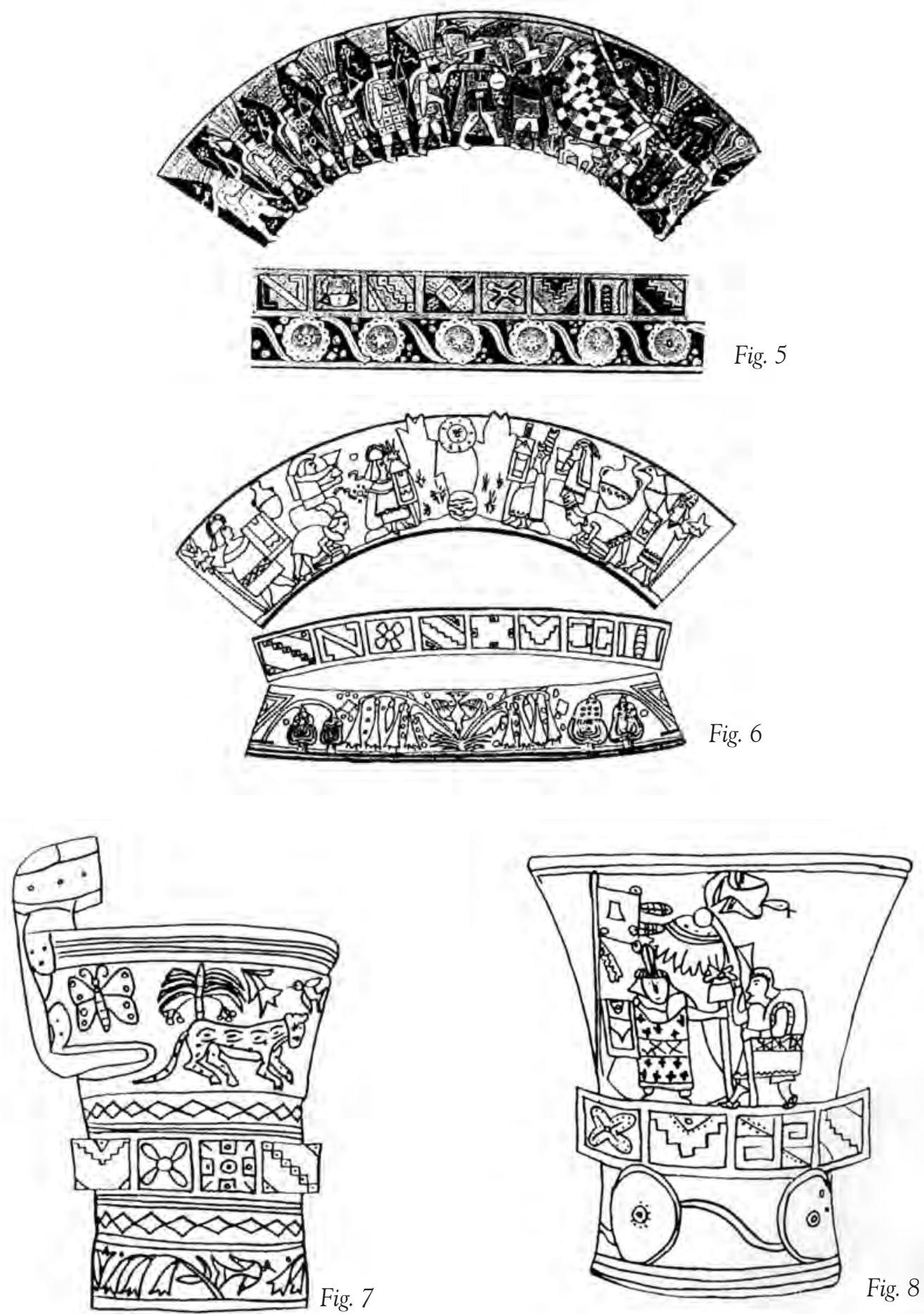


\section{ESCENAS LARGAS}
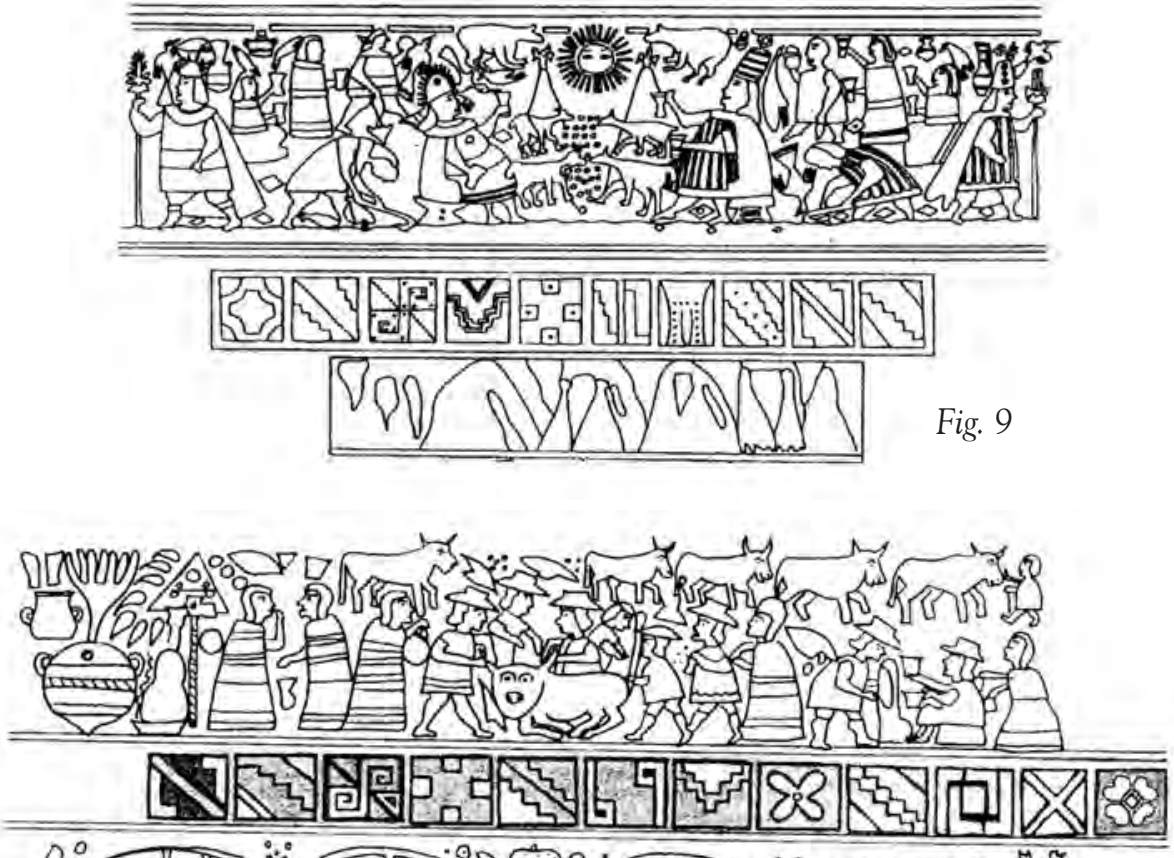

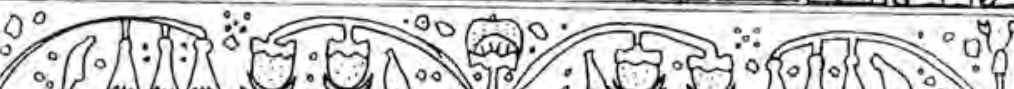
6.

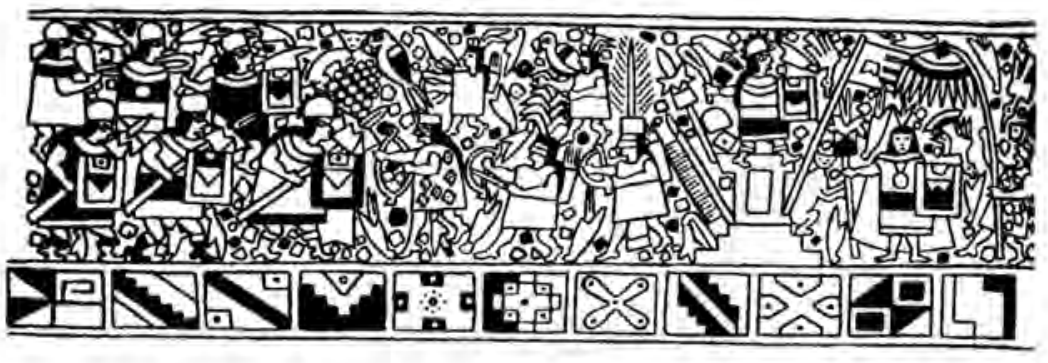

Fig. 11

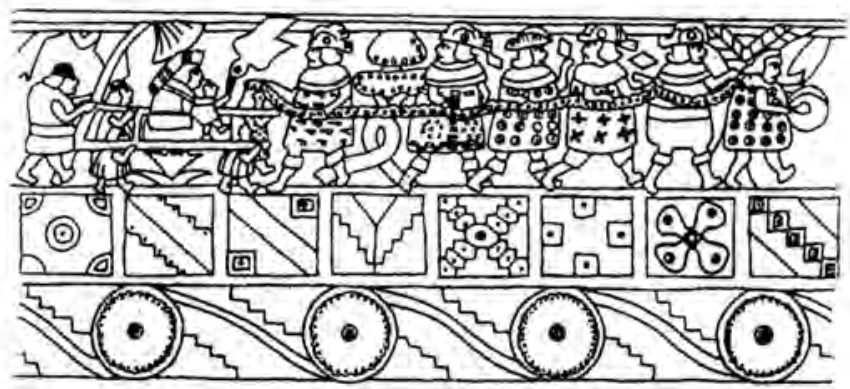

Fig. 12 


\section{ESCENAS LARGAS}
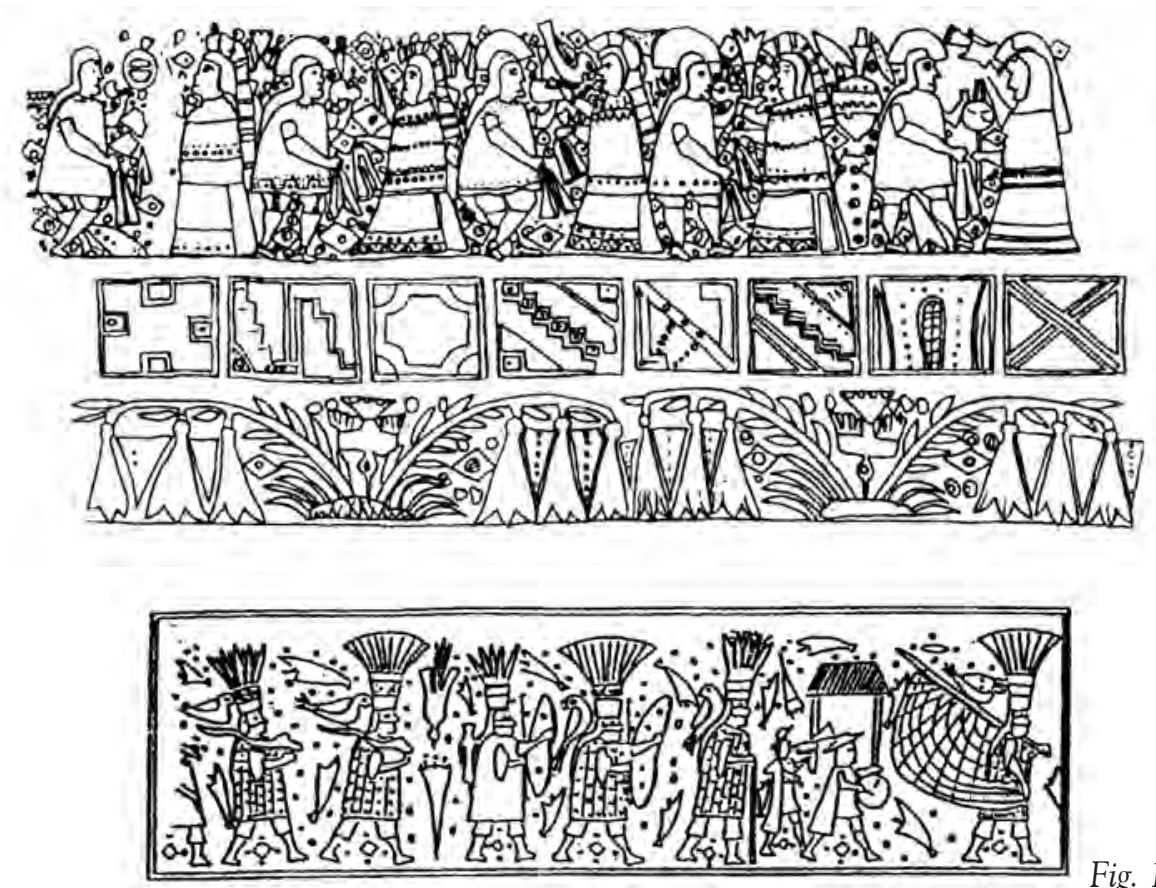

Fig. $14 a$

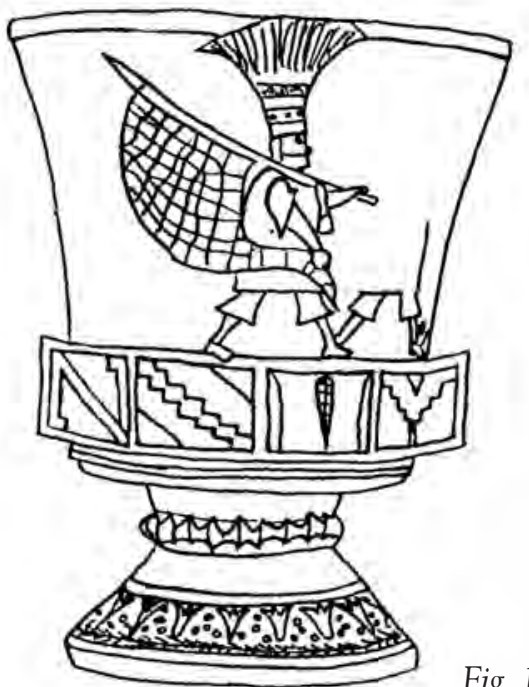

Fig. $14 b$

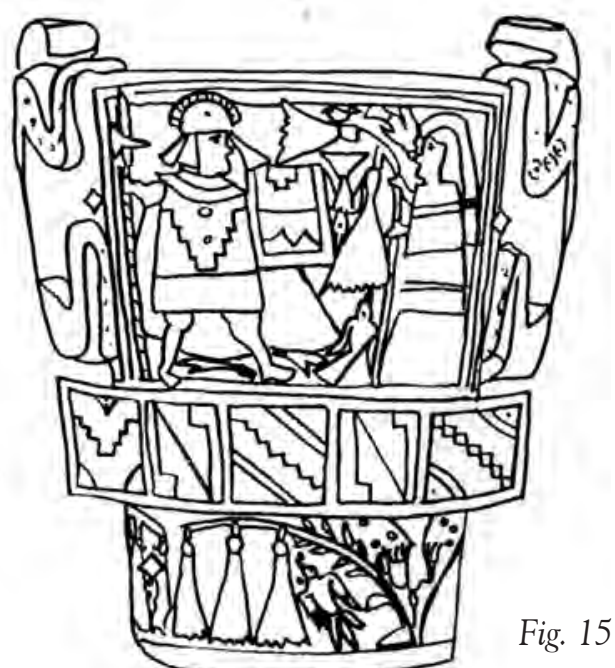


LÁMINA II. TIRAS DE TOCAPUS EN LAS “ESCENAS LARGAS”

Fig. 1

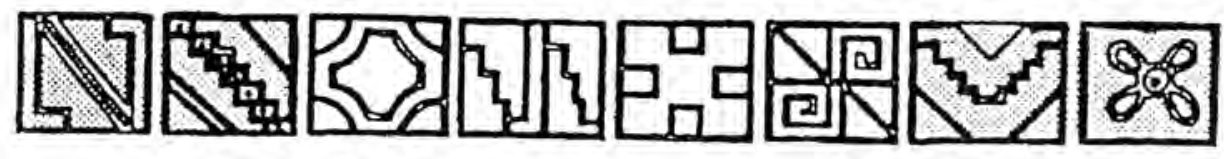

Fig. 2

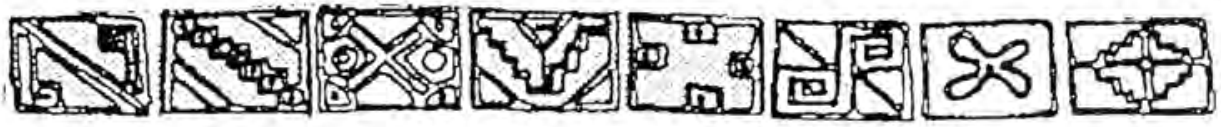

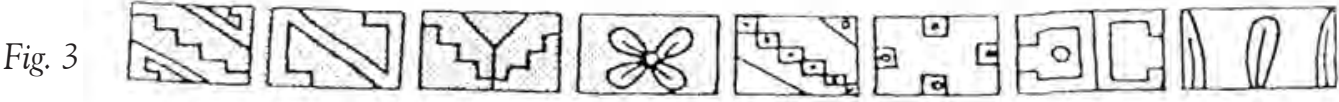

Fig. 4

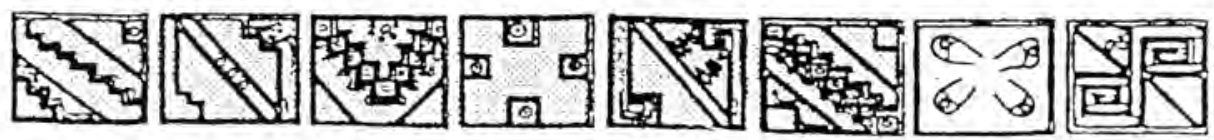

Fig. 5

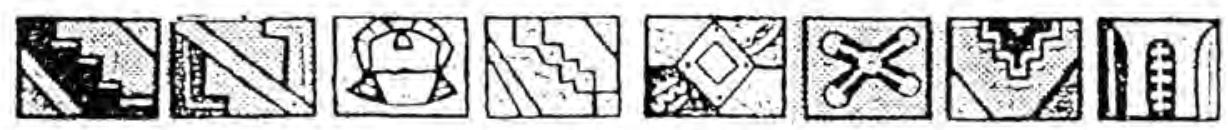

Fig. 6

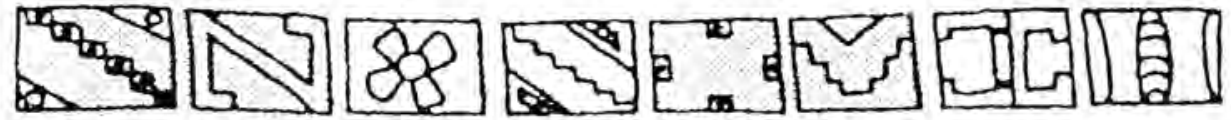

Fig. 7
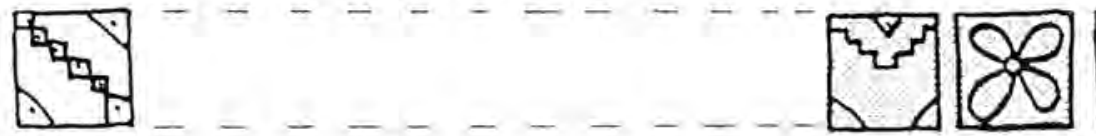

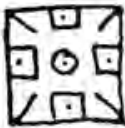

Fig. 8
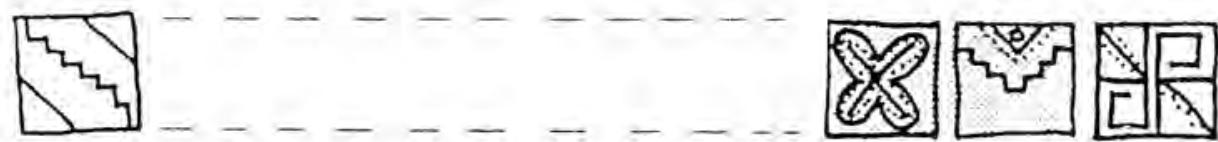

Fig. 9
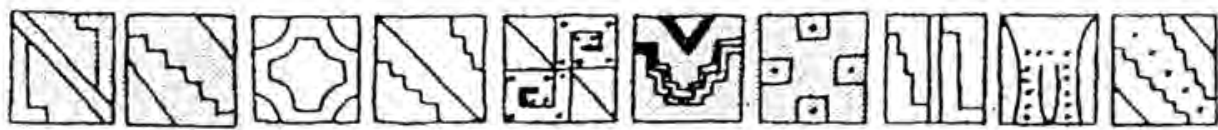
LÁMINA II. TIRAS DE TOCAPUS EN LAS “ESCENAS LARGAS”

Fig. 10

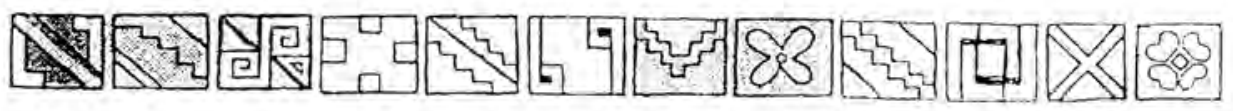

Fig. 11

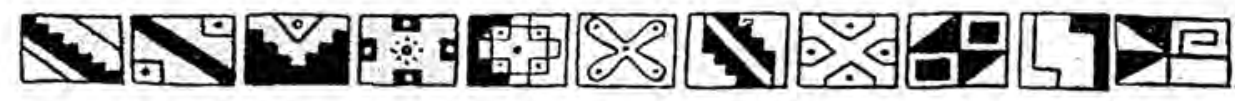

Fig. 12
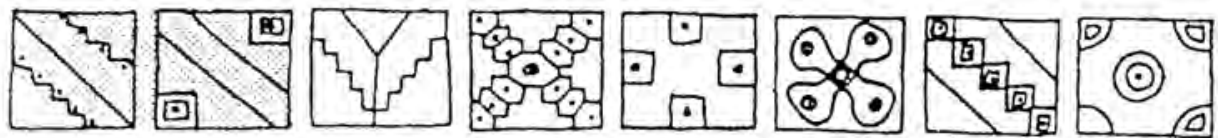

Fig. 13
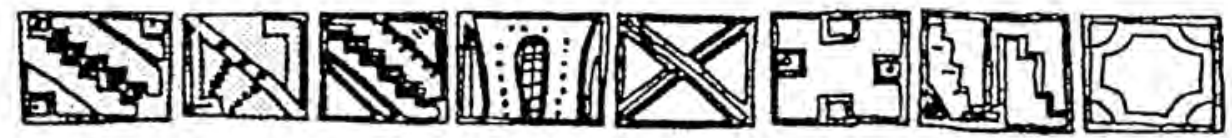

Fig. 14
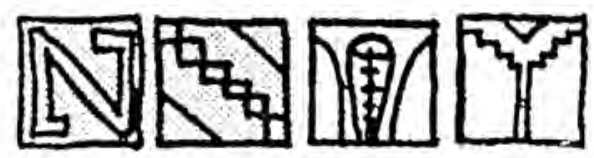

过勾

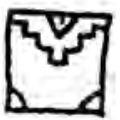

Fig. 15
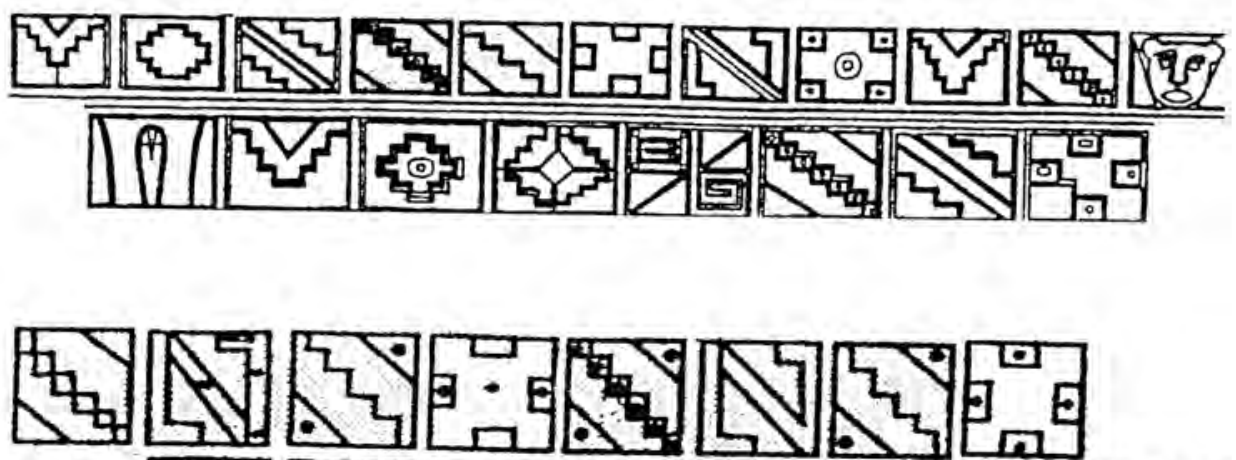

Fig. 17

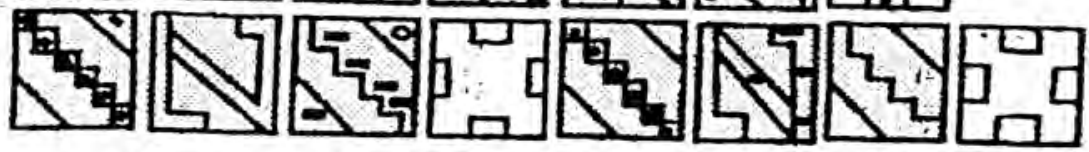


gulo se divide con líneas en formas geométricas. La división de la superficie es la creación de un espacio que está estrechamente vinculada a una cultura. Esta creación espacial está concretada por una o varias ideas base.

Si se pueden reconocer variaciones en dos tokapus, es de suponer que también puede ser así en otros tokapus. Estos motivos y su posición se puede apreciar en la lámina I. Mientras que todos estos motivos, excepto el del rombo (motivo 2), aparecen en todas las otras tiras de tokapus estudiadas, el motivo de la escalera posee un significado especial debido a su frecuencia de aparición ${ }^{15}$.

Liebscher ya ha confeccionado un catálogo de los tokapus, en el que los divide en dos grupos según los «patrones de reparto de motivos» (esquema de decoración del quero: grupo $\mathrm{B}=$ «escenas largas» y $\mathrm{C}=$ «escenas cortas»), entre los cuales constata también una diferencia. Pero Liebscher no va más allá y presenta, sin comentario alguno, solamente el gráfico con los distintos tokapus.

Tras la presentación de las variantes de los tokapus de «escenas cortas» cabe preguntarse si existe una relación entre estos cinco motivos de tokapus y los otros que aparecen en las «escenas largas», y en caso afirmativo, de qué tipo de relación se trata. Para ello me he centrado en el estudio de estos cinco motivos primeros en las «escenas largas», para poder constatar con qué frecuencia y dónde aparecen. Para este estudio ha sido importante el resultado que existen variantes de cada motivo, y que éstas se delimitan mutuamente con claridad por el trazado de las líneas. El análisis muestra que el motivo 1 aparece siempre, mientras que el motivo 2 no aparece nunca. Después de haber constatado en las «escenas cortas» que los motivos 1 y 2 aparecen a menudo juntos, vamos a ver si lo mismo ocurre en las «escenas largas.»

\section{II.3.B: «Escenas largas»}

Las «escenas largas» (figuras 1 - 17.) vienen «acompañadas» por 8 ó 10 y en un caso por 12 tokapus, en los cuales puede darse que algunos motivos se repitan, con lo que disminuye el número de tokapus diversos en una tira. También hay otra regularidad: cuatro de los once motivos están posicionados, en casi todos los casos, en un sitio fijo, cuatro de ellos forman dos pares. Este fenómeno llama la atención incluso en los pocos ejemplares presentados por mí, independientemente de las escenas que se encuentran en los vasos.

Estos cinco motivos (en una de las parejas se intercambian los motivos) han podido ser estudiados también por razón de su frecuencia de aparición. Los siguientes motivos forman parejas: 1.) el motivo 1 con el motivo 6; y 2.) el motivo 7 con el motivo 8 o motivo 9 .

\section{1) El motivo 1 con el motivo 6}

Motivo 1, «Motivo de la escalera», viene acompañado la mayoría de las veces por el motivo 6 (la $\mathrm{Z}$ «volteada»). Los motivos rodean al quero formando un círculo semejante a un cinturón, por eso las tiras no tienen principio ni final. Pero en el desarrollo debe precisarse un principio para facilitar al lector una mejor visión de conjunto. En la lámina II he posicionado esta pareja en el primer lugar, que será para mí el principio de las tiras.

\section{2) El motivo 7 con el motivo 8 o motivo 9}

Hay otro motivo que aparece frecuentemente: es el motivo del «uncu» (motivo 7). Este motivo «uncu» va combinado sobretodo con el de «la flor de cuatro pétalos» (motivo 8) o con el de los «cuatro cuadrados» (motivo 9). Otra regularidad que concierne al motivo del «uncu»: en dos queros (fig. 7 y fig. 15), que tienen una o dos asas en forma de felino, encontramos directamente debajo del asa el motivo del «unku». La posición

15 Motivos M1 - M6, Tabla I. 

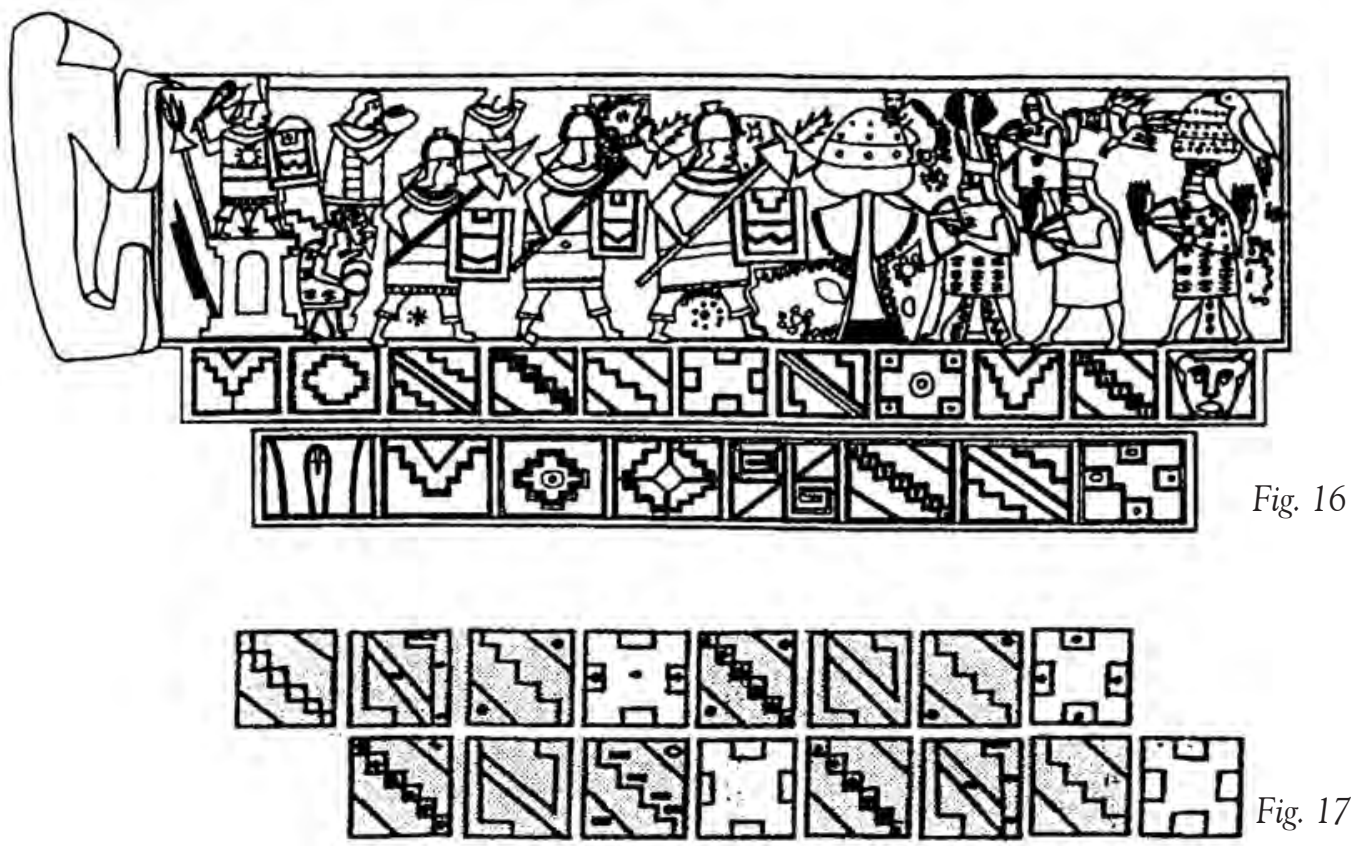

de las dos parejas aquí descritas, se puede observar en la lámina II.

En las tiras de tokapu analizadas, de 8 ó 10 posiciones, hay por lo menos cuatro $(2 \times 2)$ posiciones ocupadas por estas dos. La posición del resto de los motivos, es decir seis tokapus, no parece tener una lógica evidente. El número de tokapus es un número par, o sea divisible por dos, lo cual todavía resulta más interesante considerando que se puede observar una regularidad en la posición de ciertos pares.

Habría que pensar en que dos elementos opuestos, pero complementarios en un todo, juegan un papel básico en el imaginario del mundo andino. Es muy difícil decir algo sobre el contenido de los motivos de tokapus aquí tratados. Esta dificultad se debe a varios motivos: las tiras de tokapus que han sido aquí estudiadas como una unidad, forman parte de escenas distintas. No he conseguido constatar ninguna relación temática o ni siquiera formal entre ellas, aunque sin duda la debe haber.
Espero que a través de este trabajo se haga evidente que un estudio iconográfico solamente es posible de modo limitado, ya que, se trabaja con materiales que no representan todo el objeto sino solamente una parte de él. Es lamentable que algunos trabajos tan amplios, como, por ejemplo, el de Liebscher, a parte de las muchas representaciones escénicas, no den la posibilidad de estudiar todo el conjunto incluyendo a los queros.

\section{Algunas ideas sobre el CONTENido} DE LOS MOTIVOS BASE

Motivo 1: El motivo de "la escalera»

En las tiras de tokapus presentadas por mí aparecen principalmente dos variantes: la línea de escaleras simple y la doble. En la segunda versión, las dos líneas de escaleras no están paralelas sino colocadas la una sobre la otra, de manera que resulta de ambas una línea transversal de pequeños cuadrados. Las dos variantes pueden forman una pareja con el motivo 6 («motivo de 
la Z volteada»). No puedo demostrar con seguridad, en qué medida se trata aquí de variantes y no de dos motivos propios. Este motivo pertenece evidentemente a los más importantes. Esta afirmación se debe al hecho de que es el único motivo que aparece siempre y por eso goza, al menos visualmente, de un sitio fijo entre los otros motivos. El motivo de la escalera es uno de los más antiguos en la historia de la cultura de los Andes Centrales. Su esencia, la línea transversal, la encontramos en toda la iconografía peruana; a veces como motivo propio de una tira y en otras como elemento «de relleno» entre otras figuras.

\section{Motivo 2: «El rombo»}

El motivo 2 representa un rombo en posición vertical, trazado con línea doble. En el interior de dicho rombo hay un cuadrado al cual está inscrito un círculo. Fuera del rombo hay cuatro círculos en cada una de las esquinas. Este motivo también se encuentra dibujado en la «Relación de Antigüedades» de Pachacuti Yamqui Salcamayhua ${ }^{16}$. El texto trata del primer Inka, Manco Cápac, y es único ya que en él se utiliza el tokapu en una explicación narrada por un personaje que vivió en la época de fabricación de los queros. Leamos este texto:

«Este Ynga, lo mandó hazer a los plateros una plancha de oro fino, llano, que significase que ay Hazedor del cielo y tierra. Y era de esta manera, el qual lo hizo fixar en una cassa grande y les llamó Coricancha Pachayachachipac Uacin (Huaci= casa). Este Ynga Manco Capac fué enemigo de las uacas y como tal los destruyó al curaca Pinao Ca- pac con todos sus ydolos. Y lo mismo los venció a Tocay Capac gran ydolatra y después lo mandó que labrara al lugar do nació. Al fín los labró, los yndios por horden de Manco Capac deshaziendo la cassa y deficando canterías a manera de ventana, que eran tres ventanas que significauan la cassa de sus padres de donde descendieron; los quales se llamaron el primero Tampottoco, el segundo Marasttoco, el tercero Suticttoco que fueron de sus tios, agüelos maternos y paternos que son como este» El dibujo lleva intercalado la leyenda: «yncap tampo tocon o pacarinam yurinan cacpa unanchan, en lengua general se llama Pacarictampotoco» ${ }^{17}$.

Según H. Urteaga, Tambo Toco significa «el lugar de las tres ventanas» y Pacaritambo «la casa del producimiento» ${ }^{18}$. La traducción literal sería según Urbano y Sánchez: «ventana del tambo, lugar de origen, señal de poder» ${ }^{19}$. Según esta fuente de la época, éste sería un signo de origen de la estirpe de los incas y de su poder.

Es interesante ver que este signo no aparece en las «escenas largas». En vez de esto encontramos otro signo: el uncu con la flor de cuatro pétalos. Este a su vez sería un signo de identidad de los incas. El tokapu con el motivo «uncu»podría sustituir al motivo rombo, o mejor dicho, podría significar en las «escenas largas» algo comparable.

El hecho es que ese motivo, denominado aquí motivo número 2 , es uno de los que aparecen más frecuentemente en los tokapus de las «escenas cortas» y por eso es curioso que no se encuentre en las «escenas largas». Al observador atento le llamará la atención que este motivo aparece muy a menudo incluso en las esce-

16 Don Joan de Santa Cruz Pachacuti Yamqui Salcamaygua: Relación de antigüedades deste reino del Perú (ca. 1613) en: Urteaga 1927 y Urbano y Sánchez 1992.

17 Urbano y Sánchez, 1992: 187ss.

«Según la tradición oral de los Incas, sus antepasados míticos emergieron a la superficie de la tierra por tres o cuatro ventanas (cuevas) de un tambo (cerro) que les habría señalado Viracocha». Urbano y Sánchez 1992: 188 (40).

18 Urteaga 1927: 144 (45).

19 Traducción: tampotoco = ventana de tambo; yurini paccarini $=$ nacer, apuntar al alba, amanecer; unanchan $=$ señal; cacpa = energía, poder; pacaric tampotoco = ventana de pacaric tampo o del tambo de origen. La traducción literal: «ventana del tambo, lugar de origen, señal de poder». Según Urbano y Sánchez 1992: 188 (40). 
nas representadas, en las cuales es tomado como elemento de relleno acompañando a pájaros o motivos florales, o entre personas u otras figuras. Se dice que de este modo se representaban las hojas de coca.

Motivo 7 y motivo 8: El motivo del «uncu» y el motivo de las «flores de cuatro pétalos»

El motivo del «uncu» y el de las «flores de cuatro pétalos» que aparecen emparejados, también están relacionados por su contenido: en el Museo Inka del Cuzco se encuentra un uncu con el fondo blanco y el escote en forma de la conocida escalera en exposición ${ }^{20}$. La parte de la cintura está decorada con tres líneas de tiras de tokapus. Encima del fondo blanco, o sea más arriba y más abajo de la cintura, hay florecillas de cuatro pétalos, azules y rojas alternativamente y colocadas en fila. A parte de ese uncu hay otras pinturas de «la escuela cuzqueña» que representan también este tipo de uncus.

Aunque las flores de los tokapus están giradas en 45 grados de su punto medio, la coincidencia en la forma de flor lleva a pensar en el mismo motivo. Guaman Poma, el dibujante por antonomasia de esa época, pintó también algunas personas que llevan este tipo de uncus. Hay más variantes, pero existe una pintura ${ }^{21}$ en la que el Inka lleva el uncu con el fondo parecido a una tabla de ajedrez.

En los cuadros oscuros vemos rombos con un punto en medio y en los claros las flores de cuatro pétalos, ya comentadas. También aquí, como ocurre en el caso de los queros, los ejes de las hojas tienen forma de «X». Una vez constatado esto, se puede establecer en este caso una relación significativa entre los motivos emparejados de los tokapus. Esta relación entre ellos se puede reconocer incluso sin saber el sentido auténtico de la flor de cuatro pétalos. Análoga- mente a la pareja de motivos del uncu y de la flor, se puede decir que, aunque no sepamos el sentido del motivo de los cuatro cuadrados, es de suponer también entre ellos la existencia de una interrelación temática y visual.

El método que he utilizado no puede aclarar el significado individual de cada motivo, pero sí puede ayudar a comprender la complejidad del tokapu y facilitar, gracias a algunos reconocimientos sobre la historia de cada uno de los motivos, también la comprensión de éstos. De este modo también es posible que exista una relación coherente de contenido entre los otros pares de motivos presentados.

\section{Motivo 3: Motivo de «la pluma negra del ador- no de la cabeza del cacique»}

Además del uncu hay otro motivo que encontramos con frecuencia, y que posiblemente representa a otra insignia inka. Me refiero al motivo 3. Este motivo muestra en el medio una especie de pluma negra mirando hacia arriba. La estructura de la pluma esta marcada por líneas blancas. Alrededor de esta pluma vemos pequeños puntos blancos repartidos regularmente en una línea. Este tipo de plumas negras también las encontramos en los tocados ricamente decorados de los nobles inkas representados en las pinturas que tienen como tema la fiesta del Corpus Christi ${ }^{22}$. En las pinturas de la «escuela cuzqueña» de la segunda mitad del siglo XVII, esta pluma negra del medio lleva pequeñas piedras preciosas que vienen ordenadas a los bordes a modo de pequeños puntos.

\section{Resumen de los Resultados}

Mi estudio ha mostrado que los motivos que adornan los queros no son tan numerosos como

\footnotetext{
20 № 1/ 126, Exposición del Museo Inka.

21 Guaman Poma, 1980, Imágen No. 1057 (f.976).

22 Fotos y dibujos detallados en: Dean 1999: cap. 6 sobre «Inca (In)vestment».
} 
se piensa. En total solamente he podido diferenciar alrededor de 16 motivos. Solamente tres de ellos, con algunas excepciones insignificantes, se utilizan para «acompañar» a las «escenas cortas». Aunque en los uncus conocidos aparece un amplio grupo de motivos, en los queros que he podido estudiar solamente un número muy reducido de ellos está representado.

Comparando los motivos de tokapus de las escenas «largas» y las «cortas», se puede constatar que algunos de ellos poseen, debido a su frecuencia de aparición y su posición, un significado especial. Tras este estudio de los tokapus de los queros cabe preguntarse si este fenómeno se puede hacer extensivo a otros objetos adornados con tokapus. De todos modos, toda comparación resulta sumamente difícil. Ya he comentado que por razones técnicas no se puede hacer un desarrollo fiel a la realidad de los tokapus de los queros. Las distintas técnicas con las que se decoraban otros objetos con tokapus, hacían que variase mucho su aspecto y esas variaciones solamente se pueden diferenciar si es posible ver matices tan sutiles. En las pinturas de la «escuela cuzqueña»y en los tejidos -me refiero a las técnicas especiales de tejer los uncusse trabajaba en superficies de colores y por eso a menudo faltan las líneas básicas que nos sirven de guía al hacer un desarrollo de los queros.

Afortunadamente existe un ejemplo de tokapu -y además contemporáneo- parecido a los dibujos que aquí figuran, en el que se utilizaron solamente líneas oscuras sobre un fondo claro para hacer uncus. Son los dibujos conocidos de Guaman Poma ${ }^{23}$. Por lo que se refiere al modo gráfico de representar de Guaman Poma, hay dos aspectos que llaman la atención: por una parte marca las áreas -que en los tejidos son normalmente coloreadas-con rayas en diferentes direcciones ${ }^{24}$ (parecido a los queros precoloniales, en los cuales estos espacios están rellenados con rayas paralelas), por otra parte utiliza muy pocos motivos en comparación con los que existen en los tejidos expuestos en los museos. Entre ellos se encuentran sobre todo rombos combinados con la «Z volteada». Aquí se plantea la cuestión de si trata del conocido «inka-key», ya que este motivo aparece muy a menudo en un tipo concreto de uncus y comparte cierto parecido en la forma. Muchos ejemplares de este tipo fueron representados por J. H. Rowe ${ }^{25}$. Curiosamente no encontramos este signo relativamente fácil de copiar ni en Guaman Poma ni en los queros aquí presentados.

Entre los motivos de Guaman Poma también hay estrellas, cuadrados, cuadrados dobles, cruces y «X». Es interesante notar que también se utilizaron algunas cifras árabes como tokapu: el 3, el 4 y el 8. Según Gary Urton, debería considerarse la posibilidad de que la «Z» pudiera ser el símbolo de la cifra 226. Guaman Poma simplificó notablemente los dibujos de los motivos de los uncus (y en la representación de las cifras puede ser que incluso hiciera algunos cambios). Lo que sí coincide es la distribución de espacios de los uncus en los dibujos con la de los uncus conocidos de las colecciones. Aunque se conservaron con Guaman Poma estructuras básicas de los tokapus, éstas no bastan para llevar a cabo una comparación con los motivos de los queros. Además, como ya he dicho más arriba, los tokapus de los tejidos son mucho más complejos.

Pero volviendo a los queros y a los motivos destacados, al principio de mi trabajo he intentado reducir el grupo de queros a estudiar, dedicándome solamente a los que muestran las tiras de tokapus. Pero se estima que existe un grupo no menos pequeño que se parece mucho en la

\footnotetext{
23 Guaman Poma 1980.

24 Guaman Poma 1980. Compárese № 151, № 155 y № 40.

25 Rowe, J. H.1978.

26Urton 1997: 203.
} 
forma y en la representación de «escenas largas». La diferencia es que en lugar de tener la tira de tokapus tienen una línea de signos formada por motivos geométricos repetidos. Estos motivos son los ya conocidos rombos, la línea escalonada y la «Z volteada», llamados por Liebscher «grecas geométricas» ${ }^{27}$. Ya que pudo demostrarse la función especial de estos tres motivos, esta elección no me parece pura casualidad.

\section{INCÓGNITAS Y TAREAS}

Todavía queda sin responder en qué medida los motivos y el modo en que están ordenados cambiaron con el paso de los siglos y a partir de cuándo podemos hablar de su estilización y transformación o posible pérdida de contenido informativo. En relación al significado e interpretación de los motivos arriba mencionados, las constataciones hechas hasta aquí pueden aportar algunas ideas que amplíen los conocimientos sobre este tema.

Mientras no se haga un estudio de un grupo mayor de queros para verificar las hipótesis, preferiría abstenerme de hacer más comentarios. Una posible relación entre las escenas y las tiras de tokapus sólo podría establecerse, siempre y

Fuentes De Dibujos, COLECCIONES ${ }^{28}$

\begin{tabular}{|lll|}
\hline «Escenas cortas» \\
\hline & & \\
K1. & Flores Ochoa et al., 1998: S. 302. & Museo Inka, Universidad Nacional del Cuzco. \\
K2. & Flores Ochoa et al., 1998: S. 199 y 201. & Museo Inka, Universidad Nacional del Cuzco. \\
K3. & Cabello y Martínez, 1988: Abb.334. & Museo de América, Madrid, No Inv.: 7. 55129. \\
K4. & Flores Ochoa et al., 1998: S. 308. & Museo Arqueológico Rafael Larco Herrera, Lima. \\
K5. & Flores Ochoa et al., 1998: S. 216. & Museo Arqueológico Rafael Larco Herrera, Lima. \\
K6. & Cabello y Martínez, 1988: Abb.338. & Museo de América, Madrid, № Inv.: 7. 552. \\
K7. & Flores Ochoa et al., 1998: S. 224. & Museo Arqueológico Rafael Larco Herrera, Lima. \\
K8. & Flores Ochoa et al., 1998: S. 24. & Museo Arqueológico Rafael Larco Herrera, Lima. \\
\hline
\end{tabular}

«Escenas largas» 30

1. Flores Ochoa et al., 1998: S.219.

2. Flores Ochoa et al., 1998: S. 163.

3. Flores Ochoa et al., 1998: S. 222 y 223.

4. Cabello y Martínez, 1988: Abb. 337.

5. Flores Ochoa et al., 1988: S. 238.

6. Gisbert, 1980: Lám. 28.

7. Flores Ochoa et al., 1998: S. 83.

8. Flores Ochoa et al., 1998: S. 100.

9. $\quad$ Flores Ochoa et al., 1998: S. 166.

10. «Herscher und...», 1974: Abb. 311.
Museo de América, Madrid, № Inv.: 7. 554.

Museo Inka, Universidad Nacional del Cuzco.

Museo Nacional del Indio Americano, Washington D. C.

Museo de América, Madrid, № Inv.: 7. 561

Museo Inka, Universidad Nacional del Cuzco

Museo de Arqueología, Cuzco, № 3891-53

Museo Inka, Universidad Nacional del Cuzco

Museo Inka, Universidad Nacional del Cuzco

Museo Inka, Universidad Nacional del Cuzco

Ethnologisches Museum, Berlin

27 Liebscher 1986: 81.

28 Los números de los queros presentados son los números de las figuras. Aunque las escenas complejas no sean el tema de este artículo, se muestran aquí para dejar a los tokapus en su contexto iconográfico y también para ofrecer la posibilidad de continuar trabajando con este material.

29 Se menciona el número de inventario siempre y cuando este aparece en la fuente.

30 Figuras K3 y K6, 4, 12, 17 son redibujados y Figuras 3, 7, 8, 10, 13, 14b. y 15 han sido dibujados por la autora a 
cuando tuviéramos a nuestra disposición más desarrollos de los queros. También debería hacerse una comparación con tokapus de tejidos. Todavía queda por resolver la tarea de confeccionar una completa y comparativa catalogación de los tokapus.

\section{Agradecimientos}

Quisiera agradecer al profesor Jürgen Golte, por sus valiosas enseñanzas y apoyo. A Carolina Hohmann, por las discusiones y a Anna Betlem Borrull, por su ayuda en la traducción.

\section{BiBliografíA}

Cabello, Paz y Cruz Martínez

1988 Música y Arqueología en América Precolombina. Oxford.

Cummins, Thomas

1988 Abstraction to Narration: Kero Imagery of Peru and the Colonial Alteration of Native Identity. Los Angeles.

Dean, Carolyn

1999 Inka Bodies and the Body of Christ Corpus Christi in Colonial Cuzco, Peru. Durham and London.

De La Jara, Victoria

1972 El desciframiento de la escritura de los inkas, en: Arqueología y Sociedad, No. 7-8, Lima.

De Lavalle Vargas, José A. y Rosario de Lavalle De Cárdenas (eds.)

1999 Tejidos Milenarios del Peru - Ancient Peruvian Textile, Lima.

Flores Ochoa, Jorge A. et al.

1998 Quero-Arte Inka en Vasos Ceremoniales. Lima.

Gisbert, Teresa

1980 Iconografía y mitos indígenas en el arte. La Paz.

Guamán Poma de Ayala, Felipe J. Murra, R. Adorno y G. Urioste eds.

1980 El primer nueva corónica y buen gobierno (orig. 1615). México.
Herrscher Und Untertanen

1974 Ausstellungskatalog. Mannheim.

Kaplan, Emily y Ellen Pearlstein et al.

1999 Análisis técnico de quero pintados de los Períodos Inca y Colonial. En: Iconos, No. 2.

Kauffmann, Frederico

1978 Manual de arqueologia peruana. Lima.

Liebscher, Verena

1986 La iconografía de los quero, Lima.

Lothrop, Samuel K. et. al.

1961 Essays in Pre-Columbian Art and Archaeology. Boston.

Ramos, Luis et al.

1998 Estudio de los queros, pajchas y vasijas relacionadas. I. Encuentro Internacional de Peruanistas-Estado de los estudios histórico-sociales sobre el Perú a fines del Siglo XX. Tomo II. Lima.

Rowe, John

1961 The Chronology of Inca Wooden Cups. Essays in Pre-Columbian Art and Archaeology. Boston.

1979 Standarization in Inca Tapestry Tunics. Textile Museum Journal Vol. 17, Washington, D.C.

1999 Estandarización de las túnicas de tapiz inca (orig. 1979). Tejidos milenarios del Perú-Ancient Peruvian Textile, 2000.

Silverman, Gail

1998 El tejido andino: Un Libro de Sabiduría. Lima.

Urbano,Henrique y Ana Sánchez

1992 Antigüedades del Perú. Madrid.

Urteaga, Horacio H. (ed.)

1927 Historia de los Incas y Relación de su Gobierno. Lima.

\section{Urton, Gary}

1997 The Social Life of Numbers-A Quechua Ontology of Numbers and Philosophy of Arithmetic. Austin. 